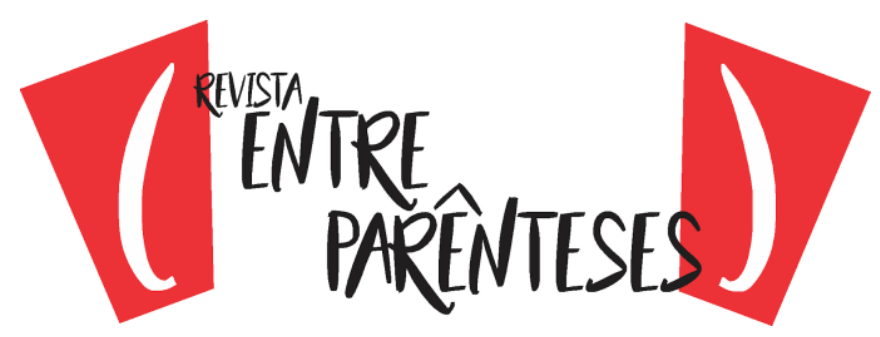

\title{
O MALANDRO JOÃO GRILO: TRAÇOS DA COMICIDADE EM GUEL ARRAES ${ }^{1}$
}

https://doi.org/10.32988/rep.v1n9.1109

\author{
Tatiana da Silva ${ }^{2}$ \\ Universidade Estadual de Santa Cruz - UESC \\ (statiana.uesc@hotmail.com) \\ Marlucia Mendes ${ }^{3}$ \\ Universidade Estadual de Santa Cruz - UESC \\ (malu.mm@gmail.com)
}

\begin{abstract}
Resumo: A presente proposta investiga traços da malandragem no personagem João Grilo na obra cinematográfica, O Auto da Compadecida, dirigido por Guel Arraes e realizado com base na obra dramatúrgica de Ariano Suassuna, com o objetivo de descrever, estudar e identificar essas marcas pertinentes do típico malandro e sua comicidade. A análise é qualitativa de caráter biblio-filmográfico e ocorre a partir dos elementos risíveis que se apresentam na referida malandrice do protagonista que envolve todos os outros núcleos em seus imbróglios. Para fundamentar a análise, busca-se suporte em Suassuna (2005), que ressalta questões relacionadas ao caricato homem sertanejo; Candido (1993), o qual traz contribuições significativas no campo da temática do personagem malandro; Bergson (1983), que analisa o riso e o cômico na representação da sociedade. Como resultado, constata-se que a jocosidade presente na narrativa fílmica está marcada por estereótipos risíveis do personagem principal. Portanto, a astúcia do típico malandro acarreta em cenas de caráter cômico, os quais proporcionam o riso na citada filmografia.
\end{abstract}

Palavras-chave: Cinema brasileiro; Cultura; Malandro; Cômico.

\section{THE TRICKSTER JOÃO GRILO: COMICALITY THAITS IN GUEL ARRAES}

Abstract: This proposal investigates João Grilo character and his trickster traits in the cinematographic work, O Auto da Compadecida, directed by Guel Arraes and based on the Ariano Suassuna's dramaturgical work, with the purpose of describing, studying and identifying these pertinent marks of the typical trickster and your comic. The analysis is qualitative of biblio-filmographic character and takes place from the laughable elements that are presented in the protagonist cunning that involves all the other nuclei in their embryglia. To support the analysis, support is sought in Suassuna (2005), which highlights issues related to the grotesque countryman; Candido (1993), who brings significant contributions in the field of the rogue character theme; Bergson (1983), who analyzes laughter and comics in the society representation. As a result, it is found that the playfulness

1 Este artigo é resultado da dissertação de mestrado do Programa de pós-graduação em Letras: Linguagens e Representações da Universidade Estadual de Santa Cruz (UESC).

${ }^{2}$ Mestranda do Programa de Pós Graduação em Letras: Linguagens e Representações (PPGL), da Universidade Estadual de Santa Cruz (UESC).

3 Possui graduação em Letras pela Pontifícia Universidade Católica do Rio de Janeiro (1978), mestrado em Artes Cênicas pela Universidade de São Paulo (1996) e doutorado em Comunicação e Semiótica pela Pontifícia Universidade Católica de São Paulo (2009). Atualmente é prof. ${ }^{a}$ - Cesupi Faculdade de llhéus, avaliador in loco institucional do Instituto Nacional de Estudos e Pesquisas Educacionais Anísio Teixeira e professor adjunta da Universidade Estadual de Santa Cruz. Desenvolve pesquisa em Comunicação e Cultura Popular.

Revista (Entre Parênteses)

Número 9, Volume 1, 2020 - ISSN 2238-4502 


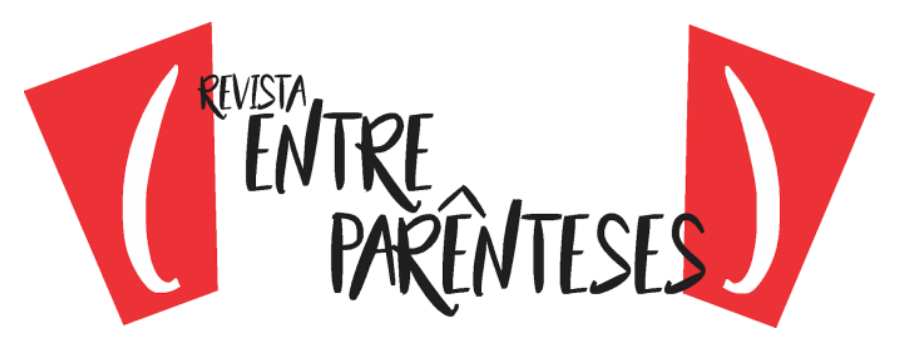

presents in the film narrative is marked by laughable stereotypes of the main character. Therefore, cunning of the typical trickster entails scenes of comic character, which provide laughter in the aforementioned filmography.

Keywords: Brazilian cinema; Culture; Trickster; Comic.

\section{EL MALANDRO JOÃO GRILO: RASGOS DE LA COMICIDAD EN GUEL ARRAES}

Resumen: Este trabajo investiga los rasgos de la picardía en el personaje João Grilo en la obra cinematográfica $O$ Auto da Compadecida, con dirección de Guel Arraes y realizada a partir de la adaptación de la obra dramatúrgica de Ariano Suassuna. Se tiene el objetivo de describir, estudiar e identificar las marcas pertinentes al típico "malandro" y su comicidad. El análisis es cualitativo de carácter biblio-filmográfico y ocurre a partir de los elementos risibles que se presentan en la referida picardía del protagonista que envuelve a todos los otros núcleos de la obra en sus trapazas. Para fundamentar el análisis, se busca el apoyo en Suassuna (2005), que resalta cuestiones relacionadas al caricato hombre sertanejo; Cândido (1993), que contribuye significativamente en el campo de la temática del personaje "malandro"; Bergson (1983), que analiza la risa y lo cómico en la representación de la sociedad. Como resultado, se constata que la jocosidad presente en la narrativa fílmica está marcada por estereotipos risibles del personaje principal. Por lo tanto, la astucia del típico malandro promueve escenas de carácter cómico, los cuales proporcionan la risa en la citada filmografía.

Palabras-clave: Cine brasileño; Cultura; Malandro; Cómico.

\section{INTRODUÇÃO}

Inúmeras são as obras literárias que se transladaram para o cinema. De fato, os textos literários sempre foram fontes de inspiração para a cinematografia, especialmente os de grande apelo popular, bastante utilizados pelo fato de representarem temas próximos da realidade do povo. Um exemplo deste tipo de adaptação é a transposição da peça Auto da Compadecida (1955), de Ariano Suassuna, no filme de nome similar, sob direção de Miguel Arraes, realizado em 2000.

Ao considerar essa relação entre cinema e literatura, propõe-se o desenvolvimento de uma proposta referente ao personagem João Grilo presente no filme de Guel Arraes, especificamente, O Auto da Compadecida, narrativa fílmica que traz à cena elementos presentes na tradição popular. Na cinematografia, notase que há uma conexão entre a trama principal e as secundárias, já que tudo na narrativa fílmica ocorre em torno do protagonista.

No referido filme, Guel Arraes revela marcas típicas da cultura nordestina, ao exibir referenciais que enaltecem as peripécias do protagonista, João Grilo, Revista (Entre Parênteses)

Número 9, Volume 1, 2020 - ISSN 2238-4502 


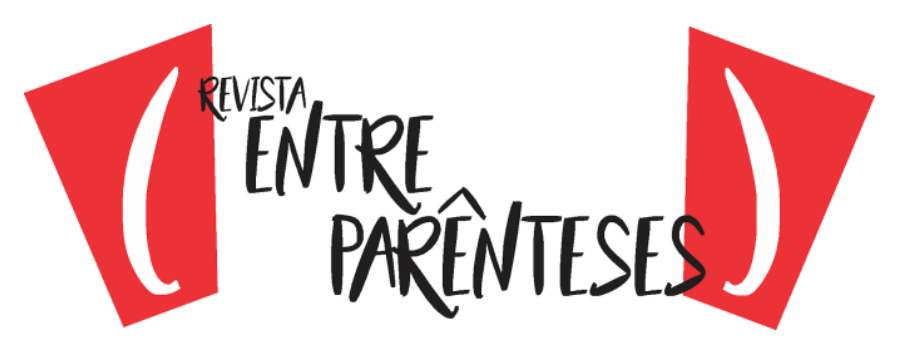

dentre os elementos mais relevantes têm-se: as problemáticas da fome e da sede, o regionalismo presente através do movimento sociológico, mais conhecido como cangaço, a tradição dos contadores de histórias presente na literatura de cordel e a religiosidade, temáticas essas conservadas da narrativa literária.

Tratar sobre a comédia $O$ auto da compadecida é trazer, à cena, as referências da literatura de cordel, a exemplo do enterro do cachorro, o cavalo que defecava dinheiro e o castigo da soberba. Os dois primeiros escritos por Leandro Gomes de Barros (1865-1918), e o último de autoria desconhecida.

$O$ enredo se desenvolve em virtude dos acontecimentos que o protagonista arquiteta junto a seu fiel escudeiro, Chicó, o qual realiza muitas armações. Dessa forma, busca-se investigar traços da malandragem de João Grilo na obra cinematográfica citada, a fim de estudar as características específicas do personagem caricato; analisar as marcas do típico malandro, relacionando-o com o protagonista do filme; identificar traços cômicos nas cenas representadas por ele.

Outro aspecto de realce na narrativa fílmica se dá pela representação do povo nordestino, na figura de João Grilo e Chicó, que vivem dificuldades em meio à miséria, mas ainda demonstram uma espiritualidade para com a vida. Os referidos protagonistas representam habitantes que buscam sempre modificar a própria realidade e não desanimam, mesmo que passem por momentos difíceis. $O$ personagem reproduz a imagem estereotipada do sertanejo rural, contudo não é a imagem do nordestino, já que se mostra como aquele que tem uma gama de saberes, sobretudo, por saber enfrentar e ser conhecedor da sua cultura, com um forte apego à religião.

Neste sentido, essa pesquisa se justifica, inicialmente, porque João Grilo é parte fundamental do Auto da Compadecida (1955), repleto de sátira e, com muita astúcia, consegue se sair bem nas mais diversas situações. Sua inteligência é muito utilizada, principalmente, quando se trata de não fazer trabalho nenhum. Tem uma lábia que acarreta na manipulação das pessoas, por apresentar um modo habilidoso e, também, pelo falar sutil. 


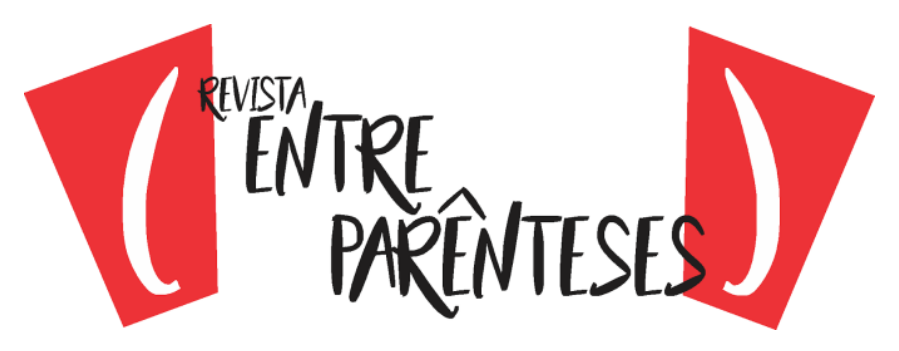

Em outras palavras, o personagem busca se aproveitar de todas as situações, especialmente, porque acaba ludibriando seus patrões, ao produzir inúmeras trapaças. A caricatura de João Grilo, assemelha-se às características de Pedro Malazartes ${ }^{4}$, típico esperto, inteligente e criativo, que tenta sobreviver à dura realidade do sertão nordestino, buscando sempre alternativas para suprir suas necessidades. Com isso, o referido protagonista se parece a essa figura, por utilizar a mentira para enganar as pessoas a sua volta.

Dessa maneira, o personagem usa da astúcia como recurso para sobreviver às adversidades que a seca e fome proporcionam, não hesita em enganar, trapacear e mentir. Porém, João mostra-se corajoso, já que não se deixa abater ante as dificuldades enfrentadas. Sempre procura uma alternativa para sanar os problemas que o circundam, de modo que o seu perfil o caracteriza como pertencente à camada popular.

Sustentando a premissa da discussão, a escolha do personagem se justifica porque suas ações promovem o riso através das mais divertidas cenas. Além disso, percebe-se que a narrativa cinematográfica se apresenta com características cômicas, pois Guel Arraes buscou conservar aspectos da obra literária, de tal forma que, acrescentou elementos de outras narrativas do citado autor, proporcionando uma intertextualidade.

Também pode-se notar que há aspectos que se aproximam do realismo fantástico que favorece para deixar o filme em uma perspectiva profunda em relação aos fatores da fé. A narrativa fílmica amplia questões relacionadas à literatura de cordel, através das peças de Suassuna inclui, sobretudo ao realçar com elementos diferentes da narrativa base, temáticas que são abordadas na obra dramatúrgica.

A metodologia pretendida no referido texto apresenta a junção entre formulações e análise. No intuito de mostrar mais acerca do principal personagem que está presente na obra fílmica, $O$ auto da compadecida, de Miguel Arraes, e também porque, pretende-se exibir sua relação com a obra literária de nome similar.

\footnotetext{
${ }^{4}$ Personagem tradicional presente na cultura portuguesa e brasileira. Sua origem caracteriza-se por ser um típico matuto, desprivilegiado, dotado de esperteza, astucia e carisma.
} 


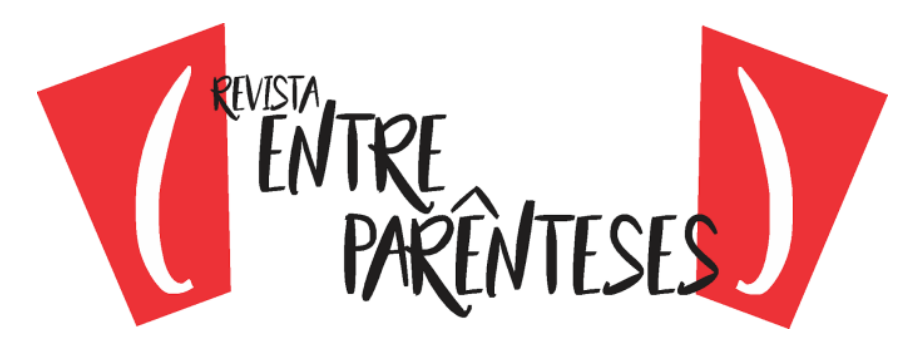

Nesta perspectiva, busca-se apresentar o personagem como aquele que usa da imaginação, caráter criativo e forte, com a finalidade de enganar o sofrimento.

Assim, a viabilidade desta proposta de estudo se realizará por meio de investigação qualitativa de caráter biblio-filmográfico, posto que consistirá em uma análise de cenas do filme, $O$ auto da compadecida, de Guel Arraes. Para tanto, serão feitas buscas em livros, além de artigos de estudo e trabalhos científicos disponíveis na internet, os quais auxiliarão na melhor compreensão da temática que contribuirá em futuras pesquisas que abarquem a temática da malandragem.

\section{JOÃo GRILO, UM PERSONAGEM CARICATO N'O AUTO DA COMPADECIDA, DE GUEL ARRAES}

O protagonista João Grilo na adaptação fílmica, O auto da compadecida, de Guel Arraes se assemelha ao homem sertanejo rural, por apresentar a pele escura que demonstra a exposição excessiva ao sol forte, indicativos que mostram a força e a bravura nesse ambiente. O personagem é, dentre outros enfoques, um pobre que sobrevive em uma região bastante árida, enquanto vaga pelo sertão junto a seu companheiro Chicó, os quais aplicam golpes e realizam negócios em meio as mentiras.

Neste contexto, as mentiras movimentam a cidade de Taperoá, a partir do humor que o protagonista João Grilo utiliza, tal qual é um recurso usado para "enganar o interlocutor, fazendo passar a mentira por verdade" (PROPP, 1992, p. 115). Sobre isso, Richard Bauman (1986, p. 12) acredita que "são necessárias investigações etnográficas de como a verdade e a mentira operam como critérios de contar histórias localmente relevantes dentro de contextos institucionais e situacionais em determinadas sociedades".

O esperto João é um homem simples, magro e fraco fisicamente, que usa da inteligência nas mais diversas situações do cotidiano. Em suas andanças, na região árida, acompanhado de Chicó, os dois discutem sobre arranjar trabalho, de modo que, o amigo do protagonista relata que a padaria da cidade está contratando 


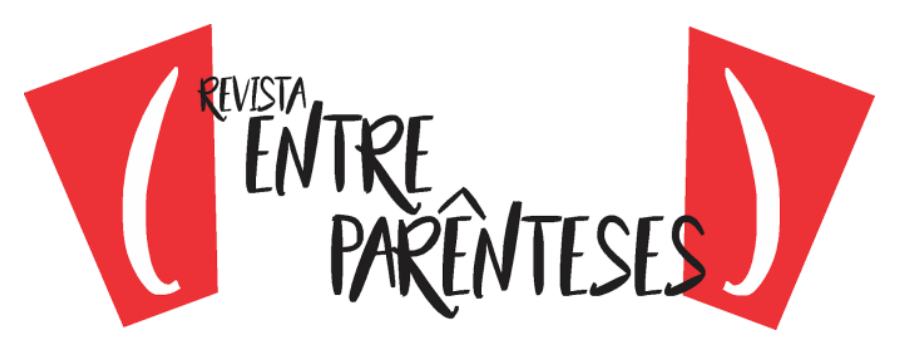

um ajudante. Na conversa, João fala que Chicó tem cara de auxiliar e com o dinheiro pago, pode ajudá-lo. Dessa forma, os dois companheiros seguem em direção a panificadora para solicitar o emprego, como pode ser observado no diálogo a seguir:

Chicó: - Ouvi dizer que o senhor está precisando de ajudante.

Eurico: - Por quê? Vocês querem ajudar, é?

Chicó: - Sim.

Eurico: - Pois pode ajudar. Ajuda e dinheiro são duas coisas que não se 'injeita'.

Chicó: - E quanto o senhor paga?

Eurico: - Eu estou fazendo o favor de deixar você me ajudar. E você quer mais o quê? (...)

João Grilo: - E quanto é o salário?

Dora: - O salário é pouco.

Eurico: - Mas, em compensação, o serviço é muito.

João Grilo: - Serviço muito tem que ter dois 'ajudante'.

Eurico: - Só se for pelo preço de um.

João Grilo: - E quanto é o preço de um? (...)

Eurico: - Cinco tustões. (...)

João Grilo: - Então vamos fazer essas contas. (...). Está arranjado. Chicó trabalha por dois, ganha o preço de um e dá conta da metade do serviço. Eu trabalho por mais dois, ganho o preço de outro e dou conta da outra metade. (...)

Chicó: - Tu tá doido, é? Agora cada um de nós vai ter que trabalhar por dois.

João Grilo: - Eu esqueci de dizer que um dos meus dois é um 'cabra' preguiçoso danado e só faz dormir o tempo todo.

Chicó: - E o outro?

João Grilo: - Ah, o outro é muito trabalhador, mas não veio hoje. (ARRAES, 2000, 00:06:05 - 00:07:47).

O astucioso João consegue o trabalho para os dois, de forma que, acaba por enganar o padeiro e sua mulher. Os patrões imaginam ter conseguido o dobro de empregados, pagando pouco, mas na verdade a contratação se dá a partir de um. Nesse sentido, Chicó questiona o parceiro sobre a situação de trabalhar a mais. Porém, Grilo afirma que uma das personalidades dele é composta por um cabra preguiçoso que só faz dormir. Sendo assim, João se mostra como um sábio que usa da arte de enganar para conseguir as coisas a seu favor. Suas mentiras afetam variadas camadas da sociedade, como a religiosa. Um exemplo é quando tenta convencer Padre João de benzer a cachorra da esposa do padeiro: 
João Grilo: - É, Chicó, o padre tem razão. Quem vai ficar engraçado é ele... E uma coisa é benzer o motor do major Antônio Moraes, outra coisa é benzer a cachorra do major Antônio Moraes.

Padre João (com as mãos nas orelhas): - Como?

João Grilo (rindo): - Eu disse que uma coisa era o motor e outra era a cachorra do major Antônio Moraes.

Padre João: - Menino, e o dono da cachorra de quem vocês estão falando é Antônio Moraes?

João Grilo: - Eu não queria vir com medo que o senhor se zangasse, mas o major é rico, poderoso. Estou trabalhando na fazenda dele e com medo de perder meu emprego, fui forçado a obedecer. Mas, eu disse a Chicó: O padre vai se zangar!

Padre João: - Zanga nada, João! Quem é o ministro de Deus para ter o direito de se zangar?

(ARRAES, 2000, 00:23:54 - 00:24:31).

O discurso usado por João Grilo apresenta uma autoridade para conseguir que o padre realize a bênção do animal, melhor dizendo, "a mentira surge de uma necessidade criativa" (HOROVITS, 2013, p. 9). Dessa maneira, o modo como é proferida a fala do personagem induz para que os outros personagens ajam em função dele. Acerca disso, Renó (2007, p. 44) afirma que:

este tipo de líder, para se manter nessa condição, possuía diferenciais diante das demais pessoas. Ele tinha mais experiências de vida e mais contato com as pessoas mais influentes, assim como João, que conhecia o major Antônio Moraes, figura icônica na cidade do Sertão paraibano.

Neste âmbito, as imagens construídas na narrativa fílmica mostram o personagem e seu comportamento em meio aos obstáculos da vida. Arraes oferece imagens de um Nordeste que tem como personagens, pessoas simples que vivem dificuldades diariamente, sobretudo em função da seca e fome. Esse ambiente é apresentado em pano de fundo para apresentar as mais ricas histórias que estão envoltas à referida região. O regionalismo expresso nas cenas destaca elementos típicos da localidade, tais como a vegetação da caatinga, a terra árida do sertão.

Levando em consideração o contexto citado, a filmografia descortina uma visão alegórica, padrão que também está presente na obra literária, sobretudo por 


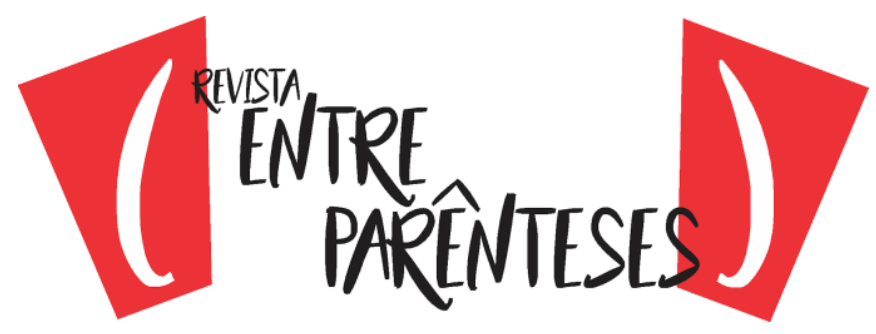

evidenciar duas percepções: uma voltada para o conformar-se e a outra em sair da região para buscar se afastar da sofrida realidade do sertão nordestino. O cenário expresso pelas artimanhas que o personagem arquiteta produz cenas divertidas e cômicas. Nesse sentido, a narrativa fílmica evidencia a essência de Suassuna - o velho palhaço e seu circo - especialmente por preservar elementos da obra dramatúrgica base.

O roteiro de Arraes traz à narrativa fílmica aspectos que diferenciam quanto à obra literária, contudo, nota-se que ele acrescenta elementos de outras obras de Suassuna a trama. Sobre isso, a roteirista Adriana Falcão explica a seguinte informação sobre o texto feito para o cinema:

O texto é de várias fontes. O Guel já mandava para mim mastigado. Ele pesquisa, ele estuda. E me mandava assim: 'Oh, tal cena aqui do Decameron, essa cena aqui é legal, tal cena aqui do próprio Ariano'. Então essa parte da pesquisa é toda do Guel, e ele sabia qual era o universo a gente escrevia as cenas. Mixamos com outros textos do Ariano. O Santo e a Porca, e uma peça, Torturas de um coração (OROFINO, 2006, p. 117).

Essa intertextualidade presente na referida cinematografia realiza uma costura no enredo, especialmente por resgatar e incluir tais fatores de outras peças de Suassuna, a exemplo de Torturas de um coração (1951); O santo e a porca (1957); A pena e a Lei (1959) e A Farsa da Boa preguiça (1960). Os referidos textos acrescidos a trama, $O$ auto da compadecida, tem como proposito preservar o caráter cômico, o qual está na obra literária, assim como também amplia a narrativa fílmica. No entender de Hutcheon (2013, p. 24),

todos esses adaptadores contam histórias a seu próprio modo. Eles utilizam as mesmas ferramentas que os contadores de histórias sempre utilizam, ou seja, eles tornam as ideias concretas ou reais, fazem seleções que não apenas simplificam, como também ampliam e vão além, fazem analogias, criticam ou mostram seu respeito, e assim por diante. As histórias que contam, entretanto, são tomadas de outros lugares, e não inteiramente inventadas.

Dentre os elementos conservados, nota-se que na primeira obra dramatúrgica citada tem a trama romanesca do triângulo amoroso que deixa a Revista (Entre Parênteses)

Número 9, Volume 1, 2020 - ISSN 2238-4502 


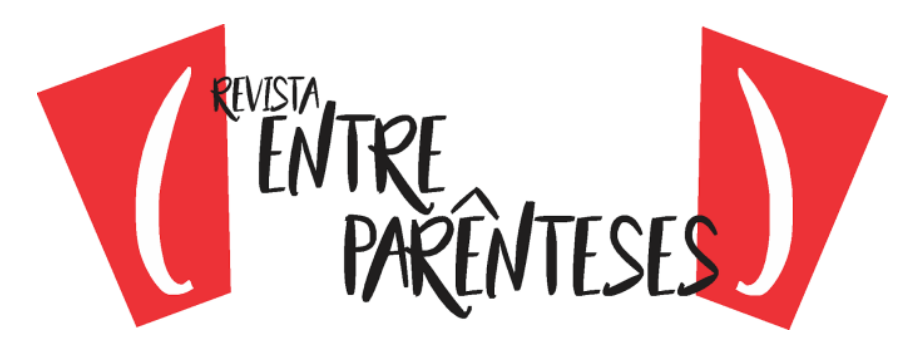

narrativa cinematográfica mais envolvente. Na segunda, Arraes traz alguns elementos relevantes, a exemplo de Eurico, as características do personagem, 0 fato da esposa dele o trair e a porca. Na terceira, pode-se perceber a presença de Vicentão e Cabo Setenta em uma espécie de "truelo". E, na última, Severino de Aracaju é apresentado, tal qual um mendigo. Sendo assim, Stam (2006, p. 21) ressalta que "a teoria da intertextualidade de Kristeva, enfatiza a interminável permutação de textualidades, ao invés da "fidelidade" de um texto posterior a um modelo anterior".

O humor expresso no filme delineia um personagem que é engraçado, principalmente por promover suas histórias e modificar a realidade dos outros personagens, que vivem nessa região. Guel Arraes descortina uma imagem caricata, melhor dizendo, o contador de histórias que exibe a simplicidade do povo nordestino em busca de sanar os dilemas sociais, que é criativo em suas narrativas, além de mostrar o quanto é hábil com a fé. Desse modo, o personagem seria uma espécie de representante da classe marginalizada, já que suas mentiras acabam por movimentar a pacata cidade de Taperoá.

Na filmografia, percebe-se que as mentiras evocam uma intencionalidade, recurso humorístico que provoca o riso. Para Moreira (2013, p. 5), essa prática apresenta "particularidades sociais, culturais, [...], mas carrega intrinsicamente um caráter universal. Todos os povos produzem humor, ele é, senão, um fenômeno cultural, reflexo das relações interpessoais que está diretamente ligado aos costumes locais".

O "amarelo" mesmo sendo um fraco fisicamente se torna um forte através de suas mentiras e histórias que tem como função expor uma alternativa para sobreviver. Esse recurso mostra a inteligência, campo muito fértil no quesito imaginação do personagem, sobretudo por converter a fragilidade em força. Dentre as jocosidades apresentadas, nota-se que "a imitação causa o riso" (BERGSON, 1983, p. 20).

À vista disso, percebe-se que o humor na filmografia delineia a desconstrução, especialmente por produzir cenas divertidas e engraçadas. Sobre 


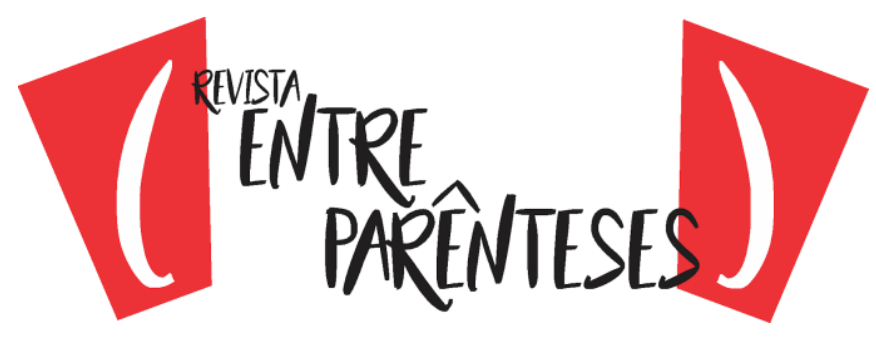

esse assunto, Moisés Massaud (2013, p. 233-234), revela que o cômico é "um processo defensivo, superior a todos os outros, o qual impede a vinda à consciência dos recalques que poderia causar sofrimento, transformando-os em motivo de prazer".

Assim, João Grilo se mostra criativo, avido à aventura, à inteligência e à imaginação, construindo enredos que o motivam a sobreviver, a exemplo de benzer a cachorra, posterior a chegada de Antônio Moraes. O personagem constrói uma narrativa interessante, ao divertir o público com adjetivos que enaltecem suas mentiras, sobretudo por tratar o padre, igualmente um louco perante o coronel, cada detalhe favorece para que a cena seguinte tenha um tom gracioso ao interlocutor.

\section{A MALANDRAGEM DE JOÃO GRILO}

O protagonista João Grilo é a representação típica do malandro que usa de todas as formas para sobreviver em um ambiente sofrido pela seca. Para Antônio Cândido, um malandro é um trickster ${ }^{5}$, que pratica "a astúcia pela astúcia" (1993, p. 3). O protagonista usa da esperteza, ao confirmar que "o sertanejo é antes de tudo um forte" (CUNHA, 1995, p. 179), aquele que consegue se desatar das amarras da vida, como no trecho a seguir:

O João Grilo é um personagem arquetípico. Ele é um personagem que partiu da cultura brasileira em geral, e nordestina em particular. (...) Ele não pode ser corajoso, não. Ele tem que ser astuto. O pobre tem que usar da esperteza para sobreviver, senão ele não resiste à seca e a fome do Sertão. No Sertão somente os mais fortes sobrevivem (SUASSUNA apud SOUZA, 2003, p. 220).

João é a representação do arquétipo brasileiro (CÂNDIDO, 1993) que se vale de sua astúcia para sobreviver. Segundo Jung (1994, p. 352), "o conceito de arquétipo [...] deriva da observação reiterada de que os mitos e os contos da literatura universal encerram temas bem definidos que reaparecem sempre e em

\footnotetext{
${ }^{5}$ Malandro.
} 


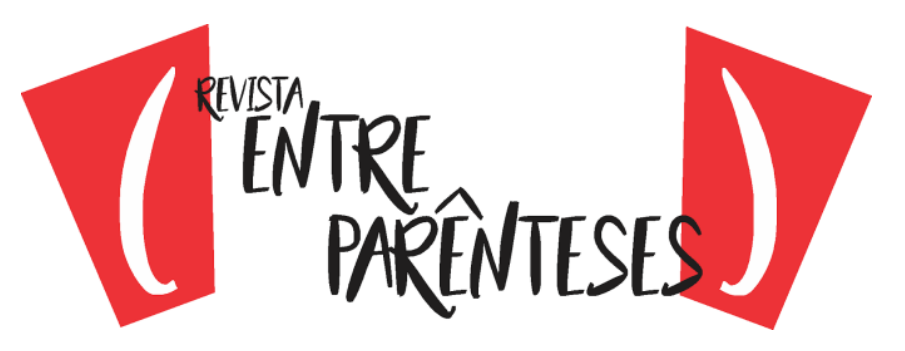

toda parte". Desse modo, "Grilo tem que lutar diariamente pelo seu sustento para conseguir alimento para o dia. No dia seguinte, ele terá que pensar em outra presepada para conseguir alimento. Essa é a figura estereotipada de João Grilo no Nordeste brasileiro" (SOUZA, 2003, p. 220).

O protagonista tem como principal característica o discurso persuasivo, especialmente, por arranjar tudo através de sua sagacidade e esperteza. Dentre as estratégias, percebe-se que a mais eficaz se mostra por meio do convencimento que acarreta nos mais variados imbróglios, uma forma de manipulação em torno das pessoas envolvidas, a exemplo do enterro da cachorra. Para da Matta (1997):

[...] o malandro é um ser deslocado das regras formais, fatalmente excluído do mercado de trabalho, aliás definido por nós como totalmente avesso ao trabalho e individualizado pelo modo de andar, falar e vestir-se. [...] no mundo da malandragem, o que conta é a voz, o sentimento e a improvisação. (p. 263; 265).

Esse tipo social rompe e quebra paradigmas por intermédio das mais inusitadas histórias. Em seus discursos, o protagonista pensa em vingar-se dos seus patrões. João Grilo, na narrativa fílmica, é vítima da seca e da condição social, sente muita raiva pela forma como é tratado pelos donos da padaria. Inclusive, há cenas em que o personagem é marginalizado e momentos em que eles o chamam de "amarelo", como no exemplo em que se disfarça, igualmente ao temido cangaceiro. Na citação a seguir, Dal Sasso (2008, p. 70) salienta essa maneira de persuasão do protagonista:

A quem João não persuade? Até mesmo no julgamento ele se intromete e dá palpites. Sugere o purgatório ao padre, ao bispo, ao padeiro e a sua esposa; pede intercessão de Nossa Senhora; zomba do diabo, dizendo ser ele um misto de tudo que ele não gosta na vida: promotor, sacristão, cachorro e soldado de polícia.

Nesse sentido, o personagem é visto como habilidoso na arte de mentir, inteligente para resolver as dificuldades, especialmente em uma terra desprovida de recursos. Em outra cena, Arraes traz para a filmografia a história da gaita mágica, ao 


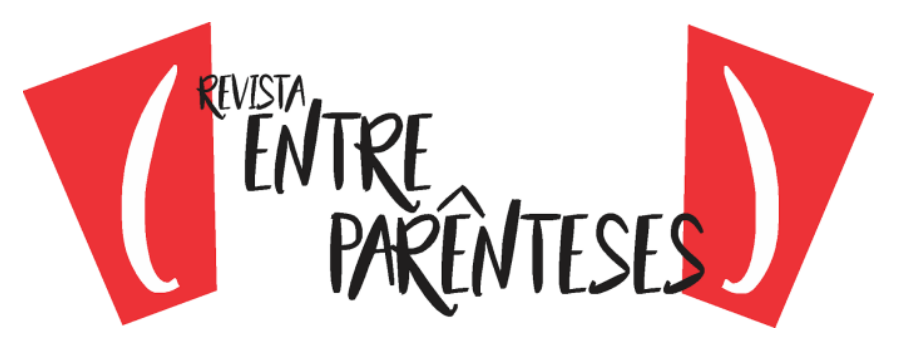

movimentar a trama cinematográfica a partir da ideia de Realismo Fantástico ${ }^{6}$, de tal forma que, os principais personagens, João Grilo e Chicó, induzem Severino para que ele queira conhecer Padre Cícero através do toque do instrumento que não ocorre após a morte.

Com isso, depois que o temido cangaceiro morre, João acaba reavendo todo o dinheiro roubado por Severino de Aracaju. Só que, ao tentar sair do tiroteio ocorrido por causa da invasão dos cangaceiros à cidade, João Grilo, o "amarelo" mais sabido, termina sendo alvejado pelo capanga de Severino. A passagem dele para o reino dos céus é embalada por meio da seguinte reflexão: "cumpriu sua sentença. Encontrou-se com o único mal irremediável, aquilo que é a marca do nosso estranho destino sobre a terra, aquele fato sem explicação que iguala tudo o que é vivo num só rebanho de condenados, porque tudo o que é vivo, morre" (SUASSUNA, 2005, p. 113). Após a chegada do personagem ao lugar que se assemelha ao paraíso, quer dizer, há uma transição, evidenciando a existência de dois planos, local em que ocorre a recuperação total de João, melhor dizendo, o tiro some, como um simples passe de mágica.

Neste contexto, Arraes conserva o viés dramatúrgico da citada obra, ao usar o principal enredo da literatura de cordel o representando no cinema. Sobre isso, Suassuna (2008, p. 180) discorre que, a narrativa "do testamento do cachorro, que aparece no Auto da compadecida, é um conto popular de origem moura e passado, com os árabes, do Norte da África para a Península Ibérica, de onde emigrou para o Nordeste". Além desses dois poemas, há outro que tem por base $O$ castigo da soberba, de autoria desconhecida, que é "marcadamente cômico", pois, "a história traz matizes do imaginário medieval que impregna a obra de Gil Vicente, outra evidente fonte de Suassuna" (HAURÉLIO, 2016, k7 . 855). Para Haurélio (2016, k. 139),

\footnotetext{
${ }^{6}$ Estilo artístico que se manifesta na literatura, embora também esteja presente em outros campos, a exemplo da pintura e do cinema. Nota-se que, o nome combina uma visão realista do mundo com a inserção de elementos mágicos, os quais são inseridos em cenários cotidianos.

${ }^{7} \mathrm{~A}$ letra "K" significa Kindle, pois a leitura e as citações estavam sendo feitas a partir do texto digital (e-book).
} 


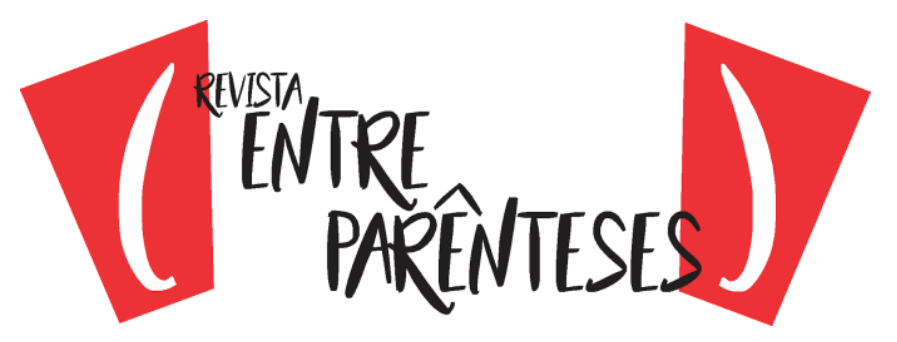

a literatura de cordel é a poesia popular, herdeira do romanceiro tradicional e, em linhas gerais, tributária da literatura oral (em especial dos contos populares), desenvolvido no Nordeste e espalhada por todo o Brasil pelas muitas diásporas sertanejas.

Tal visão, remonta o debate que, "contar histórias é sempre a arte de repetir histórias" (BENJAMIN, 1992, p. 90), bem como representa marcas da cultura e tradição oral que permite mostrar a identidade do povo. "A oralidade é entendida como fenômeno amplo e natural ao homem como a língua/linguagem que usa, é dependente da memória, coletiva e individual" (NETTO, 2008, p. 9).

Neste cenário, os principais protagonistas, João Grilo e Chicó, mostram que são hábeis na arte da palavra, especialmente em contar histórias. Essa marca da tradição oral enriquece a referida narrativa e a torna engraçada. Dizia Suassuna (2005), que:

A tradição é um imenso caldeirão de ideias (sic), histórias, imagens, falas, temas e motivos. Todos bebem desse caldo, todos recorrem a ele. Todos trazem a contribuição de seu talento individual, mas cada um vê a si próprio como apenas um a mais na linhagem de pessoas que contam e recontam as mesmas histórias, pintam e repintam as mesmas cenas, cantam e recantam os mesmos versos. Histórias, cenas e versos são sempre os mesmos, por força da tradição, mas são sempre outros, por força da visão pessoal de cada artista (SUASSUNA, p. 177).

A mentira, nesta perspectiva, é posta como artifício indispensável para a estrutura social, ou seja, através dela ocorrem melhorias em detrimento de alguns prejuízos para outros. Desse modo, Suassuna (2000) ressalta que, "a mentira é uma arte, uma fantasia, um sonho"8 necessária à vida de João Grilo e à trama. De acordo com Nietzsche (1987, p. 54),

no homem, a arte do disfarce chega a seu ápice; aqui o engano, o lisonjear, o mentir e o ludibriar, o falar por trás das costas, o representar, o viver em glória de empréstimo, o mascarar-se, a convenção dissimulante, o jogo teatral diante de outros e diante de si

8 Entrevista concedida ao programa do Jô Soares, no Recife, em 01 de dezembro de 2000. Disponível em: https://www.youtube.com/watch?v=tWjmUA2fzC0. Acesso em 14 de nov. de 2018.

Revista (Entre Parênteses)

Número 9, Volume 1, 2020 - ISSN 2238-4502 


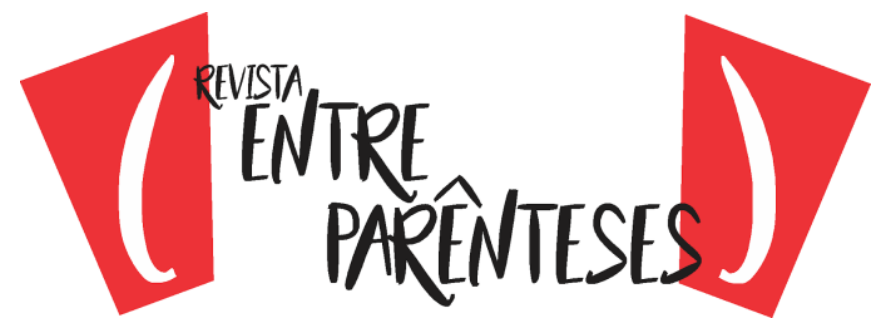

mesmo, em suma, o constante bater as asas em torno dessa única chama que é a vaidade.

A mentira é, dentre outros enfoques, um recurso muito usado na literatura. Contudo, no enredo, seu uso se restringe por atribuir à narrativa cinematográfica um tom mais cômico. Sobre isso, Propp apud Gogol (1992, p. 117) discorre que, "mentir significa dizer uma mentira com um tom tão próximo da verdade, tão natural, tão ingênuo como se pode apenas contar uma verdade - e justamente nisso está todo o cômico da mentira".

Outras obras literárias valem-se desse artificio em busca de moralizar ou ensinar, a exemplo dos livros As Mil e Uma Noites (2001); e o clássico, Dom Quixote (2017). A primeira narrativa descreve a história de Sherazade, protagonista, filha do primeiro ministro do rei Shariar, uma jovem corajosa, inteligente, que toda noite conta para o rei, seu marido, histórias fascinantes com finais em aberto, a fim de serem contados na noite seguinte para que, assim se livre da morte.

Enquanto que a segunda tem como personagem principal, Dom Quixote, um homem que perdeu a razão em virtude das muitas leituras de romances de cavalaria e acaba por imitar seus heróis preferidos. O romance narra as suas aventuras em companhia de seu fiel amigo e companheiro, Sancho Pança, que tem uma visão mais realista. Suas aventuras inventadas são sempre desmentidas pela dura realidade, efeito bastante humorístico.

Esse mecanismo tem a função de engrenar para outros acontecimentos, melhor dizendo, as mentiras provocam várias situações que deixam a narrativa mais complicada, de modo que se torna relevante contar outras ou até ampliar a mesma. Para Bergson (1983), a inteligência é uma ramificação do cômico, elemento que age junto a percepção. Dessa forma, a filmografia de Arraes modela um perfil caricato que se torna um ícone na literatura popular, especialmente por produzir o riso nas mais variadas situações com sua malandragem.

\section{TRAÇOS CÔMICOS DO MALANDRO JOÃO GRILO}




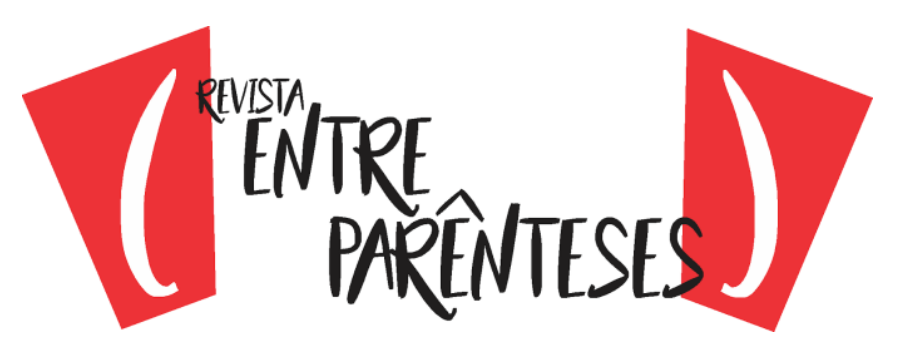

personagem se apresenta como um escultor na arte da palavra e da persuasão, sobretudo porque a linguagem usada por ele se assemelha a esperteza. Um exemplo característico desse discurso se mostra na cena em que João Grilo pede a intercessão da compadecida:

Valha-me Nossa Senhora, Mãe de Deus de Nazaré! A vaca mansa dá leite, a braba dá quando quer (...). Já fui menino, fui homem, só me falta ser mulher. Valha-me Nossa Senhora, Mãe de Deus de Nazaré!". Foi com este pequeno verso que João Grilo intercedeu pela Compadecida no dia do juízo final, reproduzido no filme de Guel Arraes. Durante todo o longa-metragem as palavras ditas pelo personagem são assim: repletas de segundas intenções, mesmo quando se trata de falar com ícones do Sagrado, como Nossa Senhora e o próprio Jesus Cristo (NASCIMENTO; MOTA, 2010, p. 8).

Toda a elocução do protagonista é bastante engraçada e cômica, já que sua inteligência se apresenta na narrativa fílmica com tons de ironia, característica pertinente à figura literária e teatral, as quais Arraes preserva no filme. Sobre esse assunto, Propp (1992, p. 125) afirma que "a ironia revela, assim alegoricamente, os defeitos daquele (ou daquilo) de que se fala. Ela constitui um dos aspectos da zombaria e nisto está sua comicidade". Para a autora Linda Hutcheon:

a ironia não adiciona meramente complicações, variedade ou riquezas a um discurso, ela faz muito mais que isso, transmitindo também algo mais, ou seja, uma atitude ou um sentimento. Dessa forma, a ironia pode ser vista como um "ato simbólico", pois, como afirma a estudiosa, "ao estabelecer um relacionamento diferencial entre 0 dito e não dito, tal ferramenta estética parece ensejar a inferência, não só de significado, mas de atitude e julgamento" (2000, p. 66).

Nesse sentido, nota-se que as mentiras arquitetadas pelo protagonista surgem da sua própria necessidade, quer dizer, diversas histórias têm a figura do pobre que mente em busca de sobreviver, de modo que, o recurso é uma arma para melhorar a própria condição. Por essa razão, as cenas em que João Grilo e Chicó provocam as maiores trapalhadas representam o aspecto de riso e a comicidade da narrativa. Segundo Propp (1992, p. 121), “a comicidade costuma estar associada ao 


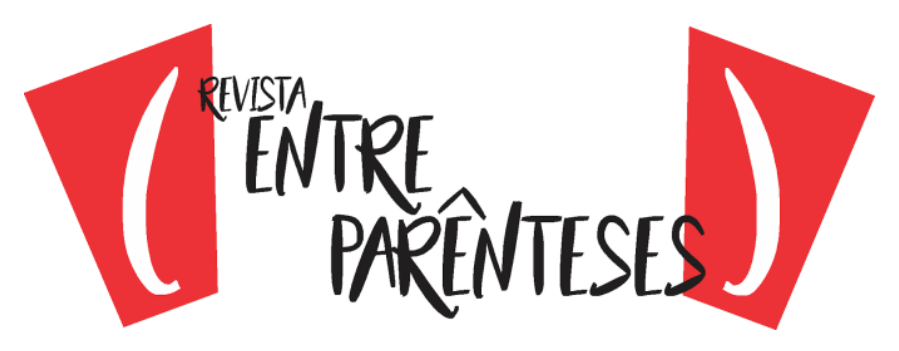

desnudamento de defeitos, manifestos ou secretos, daquele ou daquilo que suscita o riso".

A partir da referida discussão, percebe-se que o riso e a mentira são postos na narrativa cinematográfica como formas de salvação do homem. Bergson (1983) trata como um campo necessário para que o riso floresça, já que "o riso não tem maior inimigo que a emoção" (p. 7). Dessa forma, a dupla, n'O auto da compadecida, são representações importantes que provocam a diversão.

Os personagens principais revelam certas falhas morais e desvios de caráter sobre outros personagens na referida trama. Em algumas cenas, nota-se que isso é apresentado através da ironia, que segundo Lélia Pereira Duarte, "se encaixa nesse questionamento para criticar e denunciar os desvios das normas, sejam elas morais ou sociais, de modo sutil e dissimulado" (1996, p. 25). As histórias e trapaças geram narrativas engraçadas que os personagens tentam amenizar mediante a seca e a fome.

Nessa perspectiva, João Grilo representa a coragem e a criatividade, por ter um enorme desejo de viver, de maneira que sempre encontra motivos para sorrir. Determinadas situações, segundo Bergson (1983) tem a função de corrigir ou alertar o comportamento dos que vivem à sua volta. Assim, Suassuna (2005, p. 181) afirma que:

juntos, João Grilo e Chicó reproduzem a tradição circense de mostrar um palhaço espertalhão, cheio de recursos, que gosta de se meter em situações arriscadas, e outro palhaço, ingênuo, meio covarde, que se deixa influenciar pelo outro e às vezes acaba atrapalhando-o. O autor ainda salienta que, a dupla é unida pela amizade e a necessidade de sobrevivência, ao viver um misto de medo e coragem, que resultava em um tom de comédia e diversão, características de um verdadeiro circo.

João Grilo usa o riso como instrumento na luta para descaracterizar as mazelas própria do ambiente. Portanto, o personagem é o homem que sonha e não se conforma com as injustiças que o mundo impõe. O malandro movimenta a vida de outros personagens ao expor suas ideias através de suas mentiras. Assim, nota- 


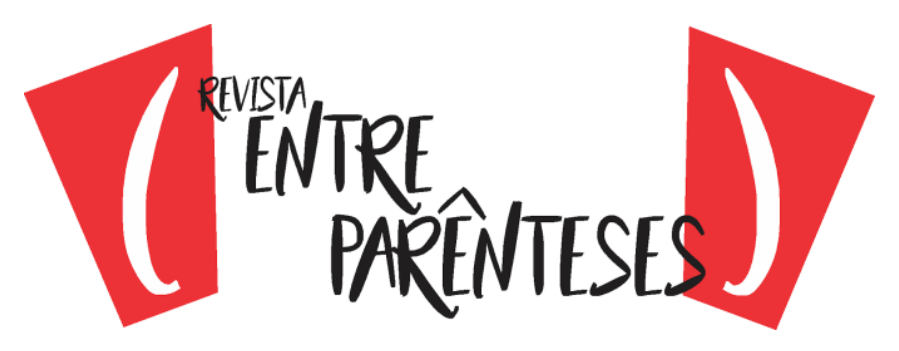

se que, a partir da obra cinematográfica, é possível ter um novo olhar diante o mundo.

O protagonista apresenta uma faceta diferente, já que esse acaba por quebrar regras, assim como ultrapassa os limites da moral e da ética. Segundo Suassuna (2005, p. 180), "João Grilo é claramente uma nova encarnação de Pedro Malazarte, talvez o nosso herói espertalhão mais conhecido". Sendo que isso, conforme Bergson (1983) discorre que "a comicidade dirige-se à inteligência pura". Desse modo, percebe-se que João Grilo ressalta os elementos mais pertinentes da sociedade de uma forma risível.

João Grilo torna-se muito engraçado e cômico, pois a cada enlace proporciona cenas bem-humoradas, especialmente porque a comicidade imita a vida (BERGSON, 1983). A partir das ideias de Suassuna, identifica-se na narrativa fílmica aspectos do literário sob uma nova ótica. O autor (2005, p. 181) ressalta que é preciso "copiar, transformando. Reutilizar, mas dando sangue novo". Recurso usado pelo próprio Arraes ao incorporar elementos diferentes do literário para 0 cinematográfico, com a inserção de outras peças de Suassuna.

Por isso, ao utilizar tipos sociais, a exemplo Severino, João Grilo e Chicó, bem como o coronel Antônio Moraes, nota-se que a narrativa apresenta uma crítica feroz à sociedade da época, mostrando que o cômico se expressa através da inversão de valores e hierarquias sociais. Assim, Zumthor (2000) espera que a mesma saiba produzir o saber lúdico a partir do riso e do cômico.

\section{CONSIDERAÇÕES FINAIS}

A presente proposta surgiu com o intuito de analisar, sob a perspectiva do esperto malandro, a representação do personagem João Grilo, no filme $O$ Auto da Compadecida (2000), de Guel Arraes. Aliado a isto, também foi objetivo deste estudo destacar as marcas que o caracterizam como um típico malandro. Para alcançar o que foi almejado, fez-se necessária uma viagem na construção d'O Auto da Compadecida (2000), dirigido por Guel Arraes. 


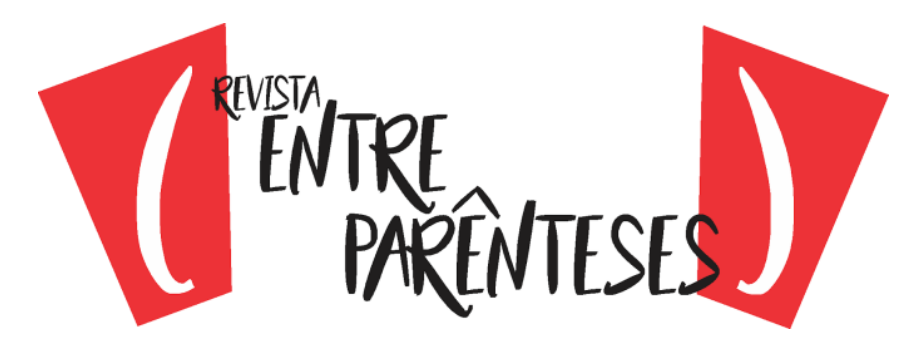

Durante o estudo, foi possível identificar que Guel Arraes conserva a mesma ótica de Ariano, ao retratar o povo que vive a dura vida do sertão, da caatinga, uma região desprovida de certos alimentos e água. Em detrimento a isso, as pessoas são fortes, felizes e sábias, como João Grilo. A partir desta proposta, pode-se perceber que os artifícios usados pelo protagonista representam uma ferramenta, para conseguir vencer em meio as adversidades do ambiente e nas interrelações sociais.

Também, pode-se confirmar que a astúcia do típico malandro acarreta em cenas de caráter cômico, sobretudo, porque o filme as condensa determinadas e realiza uma conexão com outras obras de Ariano Suassuna em uma intertextualidade com o autor literário, para ampliar o horizonte popular da obra fílmica em uma perspectiva romanesca e engraçada.

Nesse sentido, João Grilo é repleto de sapiência popular. Seus gracejos na arte da palavra apresentam uma nova perspectiva de observar o mundo. $O$ personagem se faz presente em um universo rico da cultura popular, já que o enredo que narra suas peripécias sempre foi contado e recontado na literatura de cordel. Nota-se que, com o passar do tempo, o protagonista passa a fazer parte de diferentes expressões culturais e midiáticas, ao estabelecer relação entre o acadêmico e o popular, proporcionando, assim, um anseio em se estudar esse personagem popular que se tornou carismático ao ser apresentado nas telas do cinema como a figura famosa.

A partir do estudo feito, observou-se que sob a perspectiva do malandro torna-se importante viver um dia de cada vez. Por outro lado, nas telas do cinema, Guel Arraes enaltece o cenário nordestino, ao mostrar as atitudes desse homem sertanejo, em alguns casos errados, que busca melhorar diante das mazelas da própria sociedade. Sem deixar de lado, a perspectiva religiosa que é muito forte na região nordestina.

Além disso, conhecer mais sobre o povo nordestino, a cultura dessa região seca e a construção de personagens pertencentes às camadas populares agregam valor e conhecimento. Desse modo, a obra cinematográfica evidencia duas 


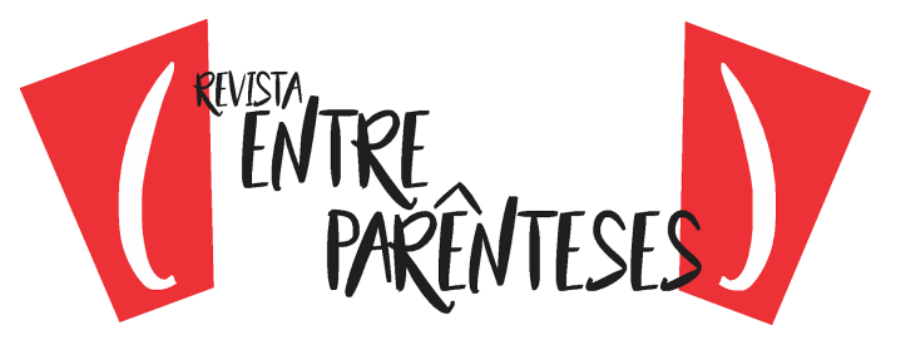

perspectivas: a tradição popular em uma mistura da literatura de cordel com a cultura erudita. À vista disso, ao incluir certos aspectos da narrativa de Suassuna, Arraes se revela, tal qual a um Griot, quer dizer, "um contador de história orais moderno", por utilizar "o cinema para contar relatos tradicionais" (CHAM, 2005, p. 297-298).

Portanto, Guel Arraes conserva a mesma temática regionalista e as problemáticas da narrativa literária. Sendo que esse dá um toque mais atual ao relacionar realidade e fiç̧ão, sobretudo, por trazer uma perspectiva do realismo fantástico. Assim, Arraes permite que a realidade esteja em conexão que explora as baixezas humanas, melhor dizendo, os tipos característicos presentes na sociedade, os quais se apresentam no discurso popular, figura caricata que representa a comicidade, ao possibilitar o humor na referida obra. 


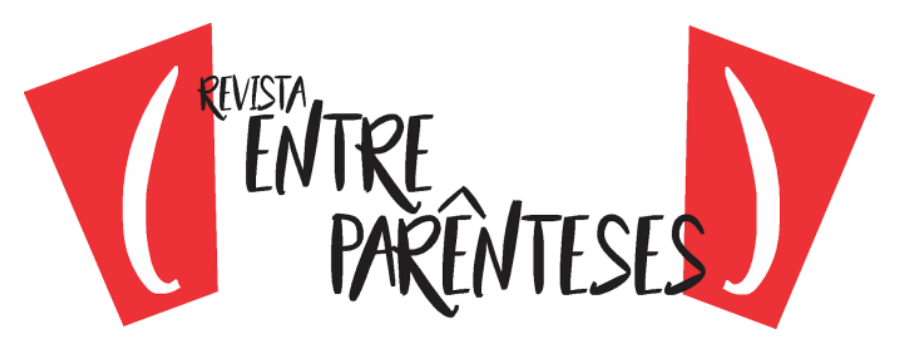

\section{Referências}

BAUMAN, Richard. Story, performance and event: contextual studies of oral narrative. Cambridge University Press, 1986.

BENJAMIN, Walter. The task of the translator. In: SCHULTE, Rainer; BIGUENET, John (Ed.). Theories of translation. Chicago: University of Chicago Press, 1992. p. 71-92.

BERGSON, Henri. O Riso: ensaio sobre a significação do cômico. $2^{2}$. ed. - Rio de Janeiro: Zahar, 1983.

CANDIDO, Antônio. "Dialética da malandragem". In: 0 discurso e a cidade. São Paulo: Duas Cidades, 1993.

CHAM, Mbye. Oral traditions, literature, and cinema in Africa. In: STAM, Robert; RAENGO, Alessandra (Ed.). Literature and film: a guide to the theory and practice of film adaptation. Oxford: Blackwell, 2005. P. 295-312.

CUNHA, Euclides da. Os sertões. In: . Obra completa. Org. Afrânio Coutinho. 2. ed. Rio de Janeiro: Nova Aguilar, 1995.

DAL SASSO, Sônia Maria. Auto da Compadecida: João Grilo e a carnavalização do sagrado. Juiz de Fora: 2008. Originalmente apresentada como dissertação de mestrado, Centro de Ensino Superior de Juiz de Fora, 2008.

DA MATTA, Roberto. Carnavais, malandros e heróis: para uma sociologia do dilema brasileiro. 6. ed. Rio de Janeiro: Rocco, 1997.

DUARTE, Lélia Parreira. Alguns Resultados Finais de Curso sobre Ironia e Humor na Literatura. Cadernos de Pesquisa vol. 16, Belo Horizonte, NAPq/FALE/UFMG, 1994.

HAURÉLIO, Marcos. Breve história da Literatura de Cordel. $2^{\mathrm{a}}$ ed. - São Paulo: Claridade, 2016. E-book

HOROVITS, Michelle Barbosa. A mentira e o riso na obra Auto da Compadecida, de Ariano Suassuna. 2013. 64 f. Dissertação (Mestrado em Literatura) Universidade de Brasília, Brasília, 2013.

HUTCHEON, Linda. Teoria e política da Ironia. Tradução: Julio Jeha. Belo Horizonte: Editora UFMG, 2000. , Linda. Uma teoria da adaptação. Tradução: André Cechinel. Florianópolis: Editora UFSC, 2013. 


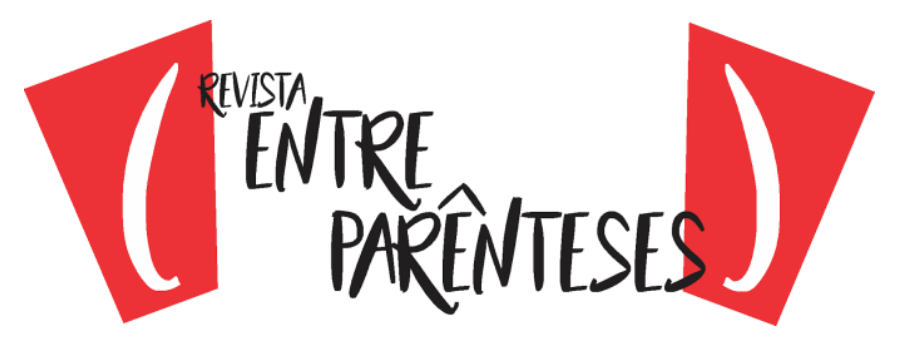

JUNG, C. G. Memórias, Sonhos e Reflexões. 16.ed. trad. Dora Ferreira da Silva. Rio de Janeiro: Nova Fronteira, 1994.

MASSAUD, Moisés. Dicionário de Termos Literários. São Paulo: Cultrix, 2013.

MOREIRA, S. T. S. O Auto da Compadecida: o humor nordestino legendado. Revista Inventário (Universidade Federal da Bahia. Online), jan-jul. 2013. Disponível em:

<<http://www.inventario.ufba.br/12/O\%20AUTO\%20DA\%20COMPADECIDA.pdf>>. Acesso em 16 de jan. de 2020.

NASCIMENTO, Joalline Carla Alves do; MOTA, Iraê Pereira. João Grilo, o amarelo mais esperto do Nordeste: Uma análise folkcomunicacional do personagem n'O Auto da Compadecida de Guel Arraes. Intercom - Sociedade Brasileira de Estudos Interdisciplinares da Comunicação XII Congresso de Ciências da Comunicação na Região Nordeste - Campina Grande - PB - 2010.

NASCIMENTO NETO, João Evangelista do. Perambulanças de João Grilo: do pícaro lusitano ao malandro brasileiro, as peripécias do (anti-)herói popular. 2014. 396 f. Tese (Doutorado em Letras) - Pontifícia Universidade Católica do Rio Grande do Sul, Porto Alegre, 2014.

NETTO, Waldemar Ferreira. Tradição Oral e produção narrativa. São Paulo: Paulistana, 2008. p. 9.

NIETZSCHE, Friedrich. Sobre verdade e mentira no sentido extra-moral (Coleção Os Pensadores). São Paulo: Nova Cultural, 1987.

O Auto da Compadecida. Direção de Guel Arraes. São Paulo: Globo Filmes, 2000. 1 DVD (105 min).

OROFINO, Maria Isabel. Mediações na produção de TV: um estudo sobre O Auto da Compadecida. Porto Alegre: Pucrs, 2006.

PROPP, Vladimir. Comicidade e riso. São Paulo: Ática, 1992.

RENÓ, Denis Porto. Agentes Folkcomunicacionais. In: GADINI, Sérgio Luiz; WOITOWICZ, Karina Janz (Org.). Noções básicas de Folkcomunicação: uma introdução aos principais termos, conceitos e expressões. Ponta Grossa: UEPG, 2007.

SILVA, Luciano Barros da. Ariano Suassuna e a origem de Chicó ou A mentira como Amor à Arte. Disponível em: <https://www.youtube.com/watch?v=tWjmUA2fzC0>. Acesso em 14 de nov. 2018. 


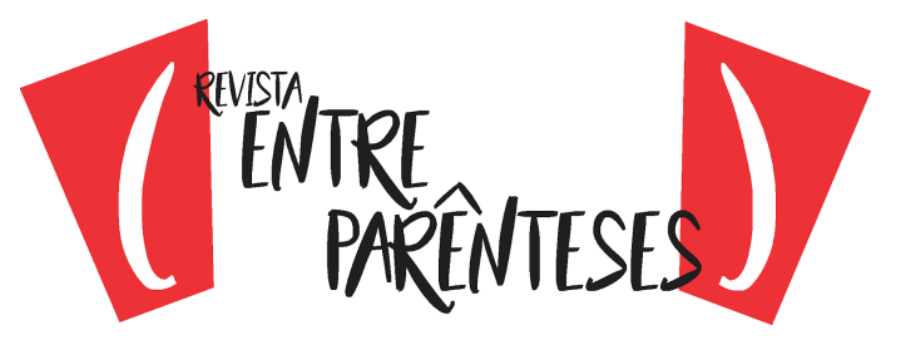

STAM, Robert. Teoria e Prática da Adaptação: da fidelidade à intertextualidade. In: Ilha do Desterro. Florianópolis, 2006. p. 19-53.

SUASSUNA, Ariano. Auto da compadecida. 35aㅡ ed., Rio de Janeiro, Agir, 2005.

Ariano. Almanaque Armorial. Seleção, organização e prefácio: Carlos Newton Júnior. Rio de Janeiro: José Olympio, 2008.

ZUMTHOR, Paul. Perfomance, percepção e leitura. Tradução: Jerusa Pires Ferreira, Suely Fenerich. São Paulo. Editora: Educ, 2000.

Recebido em: 07/03/2020

Aceito em: 10/06/2020 